\title{
El tiempo, la ciudad y la historia en la Grecia clásica
}

\author{
DOMINGO Plácido SUÁREZ \\ Universidad Complutense de Madrid
}

\section{RESUMEN}

Es simplista contraponer la idea circular del tiempo que tenían los antiguos griegos al tiempo lineal judeocristiano. En la concepción judeocristiana, el tiempo lineal aparece en combinación con una historia orientada hacia un final preestablecido y revelado. Además, también se da en esta tradición una concepción repetitiva del tiempo. Por su parte, en la Grecia clásica el concepto circular del tiempo coexistió con un tiempo histórico laico que es lineal, del que Heródoto y Tucídides fueron sus principales exponentes. Es verdad, sin embargo, que este concepto de tiempo no fue el dominante en la Antigüedad; prevaleció sobre todo en periodos de rápidas y grandes transformaciones políticas, como las que afectaron a la Atenas del siglo v a.C. No obstante, el tiempo teleológico está ausente de la tradición griega. La narración histórica, tal como hoy se la entiende, sólo nacería en el siglo XIX, en conexión con el desarrollo del capitalismo maduro. El clasicismo no puede seguir observándose como un fenómeno monolítico capaz de emitir modelos para el resto de la humanidad en su largo recorrido histórico.

Palabras clave: Tiempo cíclico, Tiempo teleológico, Tiempo lineal y laico, La ciudadEstado, Heródoto, Tucídides, Platón.

\section{SUMMARY}

It is simplistic to oppose a circular idea of time among the ancient Greeks to the linear time of the Judeo-Christian tradition. In the Judeo-Christian tradition, linear time appears in combination with a history understood as oriented toward a predetermined, revealed end. Moreover, there also appears in this tradition a concept of repetitive time. In contrast, in classical Greece the concept of circular time coexisted with that of a secular, linear historical time, of which Herodotus and Thucydides are the leading representatives. It is true, though, that this concept of time was not the prevailing one in classical Antiquity; it only dominated the literature in the periods of rapid and deep political transformations, such as those that affected Athens in the $5^{\text {th }}$ century B. C. Nonetheless, the teleological concept of time is absent in the Greek tradition. The historical narrative, as we understand it today, would only emerge in the $19^{\text {th }}$ century, in connection with the mature development of capitalism. Classicism can no longer be viewed as a monolithic phenomenon that produced models for the rest of humankind in its long historical unfolding.

Key words: Cyclical Time, Teleological Time, Secular and Linear Time, The city-state, Herodotus, Thucydides, Plato.

RDTP, LIX, 1 (2004): 157-172 
Desde los primeros siglos de la historia de Grecia como proceso operado principalmente en el ámbito de la ciudad -es decir, desde los siglos intermedios del primer milenio a.C.-, el desarrollo de los conocimientos científicos estuvo relacionado con la observación de los factores astronómicos que determinan las pautas temporales. Muchos de estos conocimientos fueron tributarios de las concepciones que sobre el mismo tema se habían desarrollado previamente en el Próximo Oriente Asiático y en Egipto, pero la peculiaridad aparece al tener en cuenta las relaciones que en Grecia estos conocimientos tuvieron con la vida de la ciudad, de la pólis, es decir, con la política.

Tanto en el plano religioso como en el cívico, las estaciones ejercían un fuerte protagonismo, que se proyecta incluso en la historia de la Guerra del Peloponeso que escribió Tucídides, dado que son los veranos e inviernos consecutivos los que marcan la pauta de los acontecimientos bélicos tanto como de los políticos. Antes del siglo v a.C., para la organización del calendario los conocimientos astronómicos obligaban a realizar intercalaciones que adecuaran las formas basadas en la percepción de los ciclos lunares a las derivadas de los ciclos solares, en un proceso en que éstos se imponían hasta el punto de llegar a prescindir de aquéllos en lo que a la organización de la vida política se refiere. Así, en Atenas, tras las reformas de Clístenes (509507 a.C.) se estableció un calendario pritánico en que sólo contaba el año solar, compuesto de diez meses organizados de modo completamente ajeno a los ciclos lunares; por ello, las fiestas religiosas, que marcaban el calendario de doce meses de base lunar, pasaron a ocupar un espacio que afectaba sólo al ámbito privado, no al funcionamiento de las instituciones. Eran precisamente las fiestas religiosas las que conservaban más sólidamente las referencias a momentos cíclicos, al conmemorar constantemente un acontecimiento cada vez que el tiempo giraba sobre sí mismo. Sin embargo, también los conocimientos astronómicos contribuían a la percepción del tiempo cíclico, al insistir sobre los movimientos circulares de los astros, tras descubrir las regularidades de la oblicuidad de la eclíptica, de los solsticios y de los equinoccios (Samuel 1972: 24). Por ello, las primeras mediciones del tiempo se concebían en términos cíclicos. Pero los calendarios cívicos tendían a funcionar de manera independiente. Los días de cada mes pritánico se designaban sucesivamente por ordinales.

No obstante, resulta evidente la necesidad de distinguir la percepción astronómica del tiempo de la percepción subjetiva del paso del tiempo. Ésta se halla sometida no sólo a la reflexión filosófica, sino a las condiciones históricas de cada época, las que permiten las variadas experiencias temporales (Janicaud 1997). En cada situación, en el plano de las civilizaciones, la percepción del tiempo ofrece modalidades diferentes. La conciencia del tiempo de las sociedades occidentales contemporáneas impide en ocasiones asimilar 
las distintas formas en que en el pasado tal percepción ha tenido lugar (Whitrow 1990: 33).

\section{FORMAS DIVERSAS DE PERCIBIR EL TIEMPO EN EL PENSAMIENTO GRIEGO}

La falta de conciencia de los cambios a lo largo del tiempo, unida a la percepción exclusiva de la sucesión de las horas del día y de la noche o de las estaciones, favorece la concepción cíclica del tiempo, donde incluso el acontecimiento final representado por la muerte se interpreta como parte de ese ciclo, como etapa en el comienzo de una nueva vida. Se explican así las similitudes presentes en las creencias correspondientes entre los rituales de muerte y de nacimiento, así como la perduración en determinadas creencias de la identidad de la muerte con el nacimiento. Ello está en la base del pensamiento órfico entre los griegos, que tanta proyección tendría en escuelas filosóficas que racionalizaban dichas creencias, como el pitagorismo o el platonismo. Las prácticas agrarias, vinculadas a los ciclos estacionales, permiten la adaptación fácil de las primitivas creencias a los intereses presentes, de modo que así se fortalecen dichas creencias como modos de mostrar las expectativas espirituales y materiales de manera indistinta. De ahí la importancia de los rituales de renovación cíclica presentes en la mayoría de las liturgias. La regulación del año agrícola es el propósito del poema hesiódico sobre Los Trabajos y los Días. Pero también, en un plano mítico, en Teogonía, 38, el poeta atribuye a las musas la capacidad de hablar sobre el presente, el futuro y el pasado: la inteligibilidad básica del partage de un tiempo lineal. Por ello, da la impresión de que en la misma civilización griega aparecen elementos suficientes para considerar que no dominaba una única forma de percibir el paso del tiempo. La corriente orficopitagórica, en la que está presente la idea del eterno retorno (Eliade 1968) y que deriva de la adecuación de los ciclos agrarios a la vida humana particular y colectiva, representa sólo una parte de la realidad. Por otro lado, entre los movimientos intelectuales arcaicos está también el de los filósofos jónicos, algunos de los cuales remontan sus preocupaciones a los orígenes, a los inicios de los tiempos, a la arché.

Existe, sin embargo, una tradición historiográfica y antropológica que considera que el tiempo histórico sólo se percibe a partir del tiempo lineal escatológico cristiano, heredado del judaísmo. Se ha puesto de manifiesto que existe cierta verdad en la percepción de la circularidad del tiempo entre los griegos (Chatelet 1962: 25), pero también que desde el principio tal imagen corresponde a corrientes específicas de pensamiento. Los griegos carecían de la imagen de un continuum que avanza desde los orígenes de los tiempos, como tienen los hebreos (Finley 1977:32); sin embargo, establecieron un tiem- 
po histórico laico, según se verá. Seguramente, la única alternativa a la circularidad de los tiempos - tal como aparece en una percepción primitiva- no se encuentra en la concepción de un tiempo unitario que se dirija hacia un final preestablecido y revelado.

Por otra parte, la narración histórica, tal como hoy se entiende, sólo nace en el siglo XIX. Sólo el desarrollo del capitalismo maduro (Thompson 1979: 239-293) permite el nacimiento de una concepción del tiempo histórico como la que dio lugar a la aparición del positivismo en esa misma época. Pero, para las épocas anteriores, no todo puede reducirse a una dicotomía donde en el pensamiento griego siempre resulta presente la idea circular del tiempo, frente a la linealidad judía, aunque tampoco aquí el proceso tiene siempre ese sentido que marca la distancia comprendida entre el principio y el final de los tiempos. Tal dicotomía responde a una concepción simplista elaborada sobre la idea de los bloques representados por las civilizaciones contrapuestas. Lo que ocurre en el judeocristianismo dominante a partir del final del mundo antiguo no es sólo que haya una linealidad temporal, sino que se impone la idea de dirección hacia un final de la historia, teleológica, que se vería rota en los tiempos modernos gracias a la Ilustración, que es precisamente la que recupera el pensamiento clásico.

Para Mircea Eliade (1968), la tendencia a reproducir arquetipos responde sobre todo a la mentalidad primitiva, sin connotaciones específicas de ninguna civilización ni, por supuesto, de ninguna etnia. Tal concepción se encuentra también en la revelación monoteísta de los judíos, a través de la regeneración cósmica al final de los tiempos (Eliade 1968: 106), a pesar de que la revelación represente un momento limitado en el tiempo.

En esta línea, es fundamental tener en cuenta la existencia de corrientes contrapuestas en el pensamiento griego, que afectan incluso a la concepción del tiempo. El clasicismo no puede seguir observándose como un fenómeno monolítico capaz de emitir modelos para el resto de la humanidad en su largo recorrido histórico. Por el contrario, su característica más destacada, frente al resto de las civilizaciones, habría sido precisamente la de haber puesto de relieve y haber hecho patente el carácter conflictivo y contradictorio de las sociedades, lo que hizo necesaria la aparición de fuertes debates ideológicos, en los que desempeña un importante papel la tendencia conservadora a imponer la regularidad, tan eficaz como para haber moldeado una imagen que se ha llegado a convertir en paradigmática.

\section{EL PENSAMIENTO HISTÓRICO EN LA GRECIA CLÁSICA}

Dentro de este ambiente, el pensamiento histórico sólo se hace posible como fenómeno del siglo v a.C., cuando las circunstancias de una ciudad, 
Atenas, favorecen el desarrollo de una conciencia capaz de percibir los cambios a través del tiempo. En cualquier caso, tal pensamiento crece en conflicto con otro pensamiento donde predomina el mito, pero también está al mismo tiempo inmerso en él: ni siquiera el pensamiento histórico se ve libre de lo que la cultura tiene de reproducción de gestos perennes en el mito y en el rito. Por ello, en la misma Atenas del siglo v, la concepción histórica del tiempo convive con concepciones antagónicas, que se reflejarán en los contrastes entre la visión de Tucídides y la de Jenofonte, éste último inmerso en la corriente representada por el platonismo como heredero del pitagorismo. La concepción histórica de Heródoto y Tucídides es en gran medida un fenómeno peculiar, como lo es el pensamiento de los sofistas en relación con la convivencia en la comunidad política.

Lo histórico como problema y como objetivo epistemológico nace de modo específico como consecuencia de las Guerras Médicas (500-479 a.C.). Los griegos mismos vieron las narraciones anteriores como despliegues impregnados de mitos, que continúan presentes en las que se califican como históricas. La cuestión estriba en determinar el papel que desempeñan en cada caso. Lo histórico como novedad se delimita por sus relaciones con el desarrollo de la política. El mito tiende a aparecer subordinado a los argumentos de tipo político que marcan la pauta. Aunque todavía Tucídides considera a Heródoto un historiador mítico, el protagonismo del proceso narrado en la obra de Heródoto se halla en el enfrentamiento entre sistemas políticos. El antagonismo que constituye el eje temático de su narración se define en los sistemas políticos, entre la ciudad libre y el despotismo oriental. Ahora bien, junto a la historia de la guerra, la obra de Heródoto está formada por una densa serie de historias locales, historias de pueblos periféricos y de ciudades griegas. Los rasgos que caracterizan la historia local en éstas son los cambios políticos que han tenido lugar, por ejemplo en Atenas (Heródoto I 59-64) (Chatelet 1962: 63). Cuando el rey Creso de Lidia, en el siglo vi a. C., quiso conocer la realidad ateniense, se encontró con que allí existía entonces una tiranía, producto de un proceso histórico complejo en que se involucraban las fuerzas sociales de la ciudad y cuyo resultado final respondía a una lógica perfectamente comprensible en el plano histórico, como sucesión de diversas circunstancias. Luego (Heródoto I 65-68), también la formación del sistema espartano se relata de modo cronológicamente coherente en sus diferentes etapas, a pesar de que el relato experimenta diferentes retrocesos en el tiempo, que hacen que pierda su coherencia.

Por ello, si puede admitirse la existencia de cierta idea de la circularidad del tiempo en algunas manifestaciones del pensamiento y de las mentalidades de las que caracterizan el mundo griego y, en cierta medida, le han creado una fama universal, en cambio, en la historiografía griega, no hay constancia 
de que predominara una idea cíclica del desarrollo histórico, al menos desde que el género existe como tal. Que el desarrollo histórico que ofrece Heródoto no sea milenarista ni se dirija a un fin - rasgo que a veces se atribuye a la concepción judeocristiana como modo alternativo de percibir el tiempo- no quiere decir que responda a una concepción cíclica. No es posible plantear la teoría del tiempo como si sólo existieran estas dos alternativas: el milenarismo o el eterno retorno. En Heródoto no puede defenderse la interpretación de que hay ciclos temporales que marquen el proceso general (Momigliano 1969: 25). Las Guerras Médicas tienen un significado único. Pero también lo tienen los acontecimientos que configuran la historia de cualquiera de las ciudades o pueblos tratados. En este sentido, tenía razón Aristóteles cuando en su Poética (IX=1451b5-11) consideraba la poesía más filosófica que la historia, porque ésta se ocupa de lo particular. Para los antiguos, lo mítico y poético tiene un carácter más paradigmático y por ello los héroes de la épica reaparecen constantemente en la tragedia (Finley 1977: 15). Los personajes históricos eran, en cambio, únicos.

En Heródoto, el tiempo mítico queda al margen de las explicaciones históricas (Plácido Suárez 1986: 38). Por ello, el pasado histórico para los griegos era más corto que para los egipcios, que integraban en su tradición histórica todas las genealogías. Tucídides no admira la antigüedad cuando trata de valorar un sistema político (Tucídides VIII 97, 2). Así, cuando se estableció el régimen de los Cinco Mil en 411 a.C., escribe que "fue ahora la primera vez, al menos por cuanto se refiere a mi época, que los atenienses se gobernaron bastante bien" ${ }^{1}$. Los acontecimientos ocurren una sola vez y se valoran en su momento, tanto los de las grandes guerras como las vicisitudes políticas locales.

\section{HERÓDOTO}

Lo histórico, y por tanto capaz de explicar el presente, se inicia para Heródoto en el tratamiento de figuras como Polícrates de Samos y el rey Creso (I 6). Tras las referencias míticas, dice que Creso fue el primero que emprendió una acción imperialista que condujo a la guerra: "El tal Creso fue, que nosotros sepamos, el primer bárbaro que sometió a algunos griegos, obligándoles al pago de tributo..." ${ }^{2}$. Las referencias míticas a los enfrentamientos entre Oriente y Occidente con motivo de los raptos de mujeres

\footnotetext{
${ }^{1}$ La traducción de esta cita y las demás de Tucídides que aparecen en este artículo son de A. Guzmán.

${ }^{2}$ La traducción de esta cita y las demás de Heródoto en este artículo se deben a C. Schrader.
} 
quedan relegadas a una introducción literaria. Polícrates aparece, por su parte, como el primero que pensó en el imperio marítimo, aparte de Minos (III 122) (Finley 1977: 22): "En efecto, Polícrates fue, que sepamos, el primer griego - sin contar a Minos de Cnoso y a algún otro, si en realidad lo hubo, que detentara el dominio del mar con anterioridad a este último- que aspiró a conseguir la hegemonía marítima". Y el historiador marca la diferencia de manera explícita: "Es decir, en la llamada época humana, el primero fue Polícrates...". En la obra de Heródoto, el proceso histórico relega al tiempo mítico, en que podían admitirse los procesos cíclicos. El llamado "Padre de la historia" también se propone contar cómo alcanzaron los persas la hegemonía (I 95). "A partir de este punto, nuestro relato va a contar, por lo tanto, quién era el tal Ciro, que destruyó el imperio de Creso, y cómo los persas llegaron a adueñarse de Asia". El relato sucesivo se enmarca dentro de un conjunto de relaciones temporales bien definidas en la duración. La historia de Minos queda en cambio rechazada como parte de las talasocracias. Heródoto cuenta narraciones míticas, pero no las incluye como parte del proceso de explicación histórica. El interés por el tiempo queda patente desde el principio de la obra, en el Proemio, donde declara que escribe para evitar que, con el tiempo, los hechos humanos queden en el olvido (Chatelet 1962: 28). Son históricas las acciones de los seres humanos frente a la atemporalidad del mito. Se trata de que no caiga en el olvido el pasado real. El proceso resulta paralelo al de la historización del héroe, cuando es el conjunto de los ciudadanos el que merece los honores que se conceden por la victoria. En el relato de Heródoto se opera el proceso de politización de la tradición heroica que da lugar a la aparición de la historia frente al mito, del mismo modo que el túmulo de Maratón significa la sustitución del héroe individual por el héroe colectivo representado por el conjunto de la ciudadanía.

Por ello, para las acciones relacionadas con esa guerra política, se busca un encadenamiento temporal comprensible. La actitud de Creso en 546/7 se presenta como antecedente de un choque que se manifiesta como modo de comportamiento de los imperios, del lidio al persa, pero que se desarrollará hasta manifestarse como imperio ateniense. El desarrollo se hace desde el principio inteligible en el relato mismo. Todo lo que ocurre es nuevo, aunque se halle vinculado al pasado en su desarrollo lógico, no porque repita ningún tipo de acción que le sirva de modelo. La talasocracia minoica no sirve como precedente, al situarse en un tiempo mítico ahistórico. En el tiempo histórico, en cambio, las decisiones humanas conllevan consecuencias trascendentes. Todo en la historia es nuevo después de las Guerras Médicas. El antes y el después quedan claramente definidos. A partir de ahora, la tendencia a la hegemonía que destruye el imperio persa puede ser causa de la destrucción de Atenas, porque la victoria lleva al imperialismo que puede 
tener esas consecuencias, porque Atenas también se hace potencia esclavizadora, como lo era el imperio persa (Plácido Suárez 1999a). Se revela así una especie de ley del proceso histórico (Chatelet 1962: 94), derivada de una situación nueva, que se desprende de la aparición de los imperialismos, fenómeno nuevo que no repite situaciones en procesos cíclicos.

Para Heródoto, en efecto, nada se repite (I 32) (Mazzarino 1974: II, 2, 415). "De la totalidad de los días...", dice citando a Solón, "no hay uno solo que conlleve situaciones totalmente semejantes a las de otro día cualquiera". En las referencias al pasado, se trata más bien de los antecedentes del presente que pueden referirse a un pasado mítico, como los conflictos entre Oriente y Occidente que preceden a las Guerras Médicas. De este modo, las diferencias entre Oriente y Occidente adquieren un sentido perenne, que se remontan a la época mítica, aunque los imperialismos nacen en época histórica. Por tanto, si es cierto que hay concepciones cíclicas en el pensamiento griego, éstas son objeto de crítica al menos desde Demócrito (VidalNaquet 1981: 80). En la concepción de éste último, se insiste por el contrario en la imagen de la civilización como invención de los hombres y, por tanto, como algo nuevo, no sometido a ningún tipo de ciclo.

No es fácil, de todos modos, distinguir siempre en el pensamiento de los griegos entre "temps des dieux" y "temps des hommes", según la propuesta de Vidal-Naquet (Mazzarino 1974: II, 2, 458-460). No se produjo una transformación tan nítida. En el desarrollo de la pólis, el tiempo mítico sigue estando presente en los rituales, como en los misterios eleusinios, donde se reproduce cíclicamente un proceso que se señala como pasado, pero realmente se revela como atemporal, sólo sometido a la ciclicidad estacional que justifica los rituales. La presencia de la historia mítica se manifiesta en relación con la representación de los rituales totémicos primitivos (Thomson 1946). Su vigencia se revela especialmente activa en los festivales dramáticos, a pesar de que éstos se insertan plenamente en el mundo de la ciudad democrática. Se trata de un intento de pautar el tiempo sobre modelos primitivos, prestigiosos e ideológicamente eficaces, lo que se inserta dentro de una determinada concepción de la realidad histórica; pues ambas concepciones, mítica e histórica, conviven en el mundo griego, como en Atenas conviven un calendario religioso y uno político. En ello se revela una vez más el carácter de la cultura griega como escenario de contradicciones enormemente vitalizadoras. La racionalidad democrática convive con la irracionalidad mítica, vigente en el mundo de los festivales y rituales. La ciudad democrática hace uso del arcaísmo a favor de su propia supervivencia (Plácido Suárez 1999b). 


\section{TUCÍDIDES}

Para Tucídides, en cambio, lo mítico sirve para explicar el presente de modo analógico. El presente está integrado en el continuum de los acontecimientos del pasado. Si Heródoto busca causas en el pasado remoto para explicar las diferencias entre Oriente y Occidente, para Tucídides el pasado remoto tiene más bien valor como referencia analógica: no es que la historia se repita, es que siempre están presentes los mismos factores, que reaparecen sobre todo en las guerras. Las motivaciones humanas coinciden en el tiempo mítico y en el tiempo histórico, como ocurre con el imperialismo, minoico o ateniense. Las guerras producen los mismos efectos, que revelan la naturaleza humana. Ahora bien, el acontecimiento de la Guerra del Peloponeso (431-404 a.C.) es en sí único, lo cual es perfectamente compatible con la conciencia de que el presente es resultado del pasado (Chatelet 1962: 104). Por eso el pasado sirve para explicar el presente, no porque en la guerra se reproduzca el pasado sino porque es su resultado.

En cierto modo, Tucídides puede definirse en términos modernos como un evolucionista (Hunter 1982: 102), lo que explica que algún autor contemporáneo se sienta sorprendido por la modernidad del ateniense. A este propósito, Janicaud comenta que "il est incontestable que les Grecs sont les inventeurs de l'histoire au sens où nous l'entendons, ce qui suppose l'émergence d'une conscience chronologique, le surgissement de Chronos" (Janicaud 1997: 247) ${ }^{3}$.

La Pentecontecia, el período de hegemonía de Atenas en el siglo v, sirve por ello para explicar la alethestáte próphasis, la verdadera causa (Chatelet 1962: 113). La verdadera causa de la Guerra del Peloponeso se hallaba en el proceso histórico que había conducido a que los griegos cobraran miedo al imperialismo ateniense. La idea evolutiva a más largo plazo aparece claramente en los capítulos dedicados a la Arqueología en la obra de Tucídides, donde los seres humanos se organizan a partir de un estado primitivo, sin necesidad de participación divina, como también ocurre en Demócrito (en Diels y Kranz 1954: 68B5, 3). El desarrollo del hombre se produce a causa de su propia relación con la naturaleza. La introducción del tiempo como factor de desarrollo va unida a las líneas de pensamiento que prescinden del mito como tal factor. En cierta medida, una lógica sustituye a la otra. Por ello la concepción lineal va unida a las corrientes de pensamiento más vinculadas a

\footnotetext{
${ }^{3}$ Traducción castellana: "No hay duda de que los griegos son los inventores de la historia en el sentido en que nosotros la entendemos, lo que supone el surgimiento de una conciencia cronológica, el nacimiento de Cronom. (Nota del editor.)
} 
la concepción progresiva de la ciudad y de sus estructuras de convivencia. De este modo, no resulta sorprendente que también sea claramente evolutivo el proceso señalado por Protágoras en el mito de Prometeo reproducido por Platón en su diálogo Protágoras, 321Ass. (Castoriadis 1999: 120). El mito, como explica el mismo Protágoras, se presenta como una narración embellecida del razonamiento que también aparece en el diálogo. Aquí la forma mítica expone una evolución clara desde la incapacidad de convivencia de los hombres hasta la ciudad democrática (Plácido Suárez 1984).

En la corriente ilustrada que se vincula al desarrollo de la ciudad democrática, el pasado - mítico o histórico- sirve para comprender el presente; por el contrario, Jenofonte, de la escuela socrática, busca modelos en el pasado (Chatelet 1962: 304): lo que representa el origen de una tradición moralizante que pervivirá en Occidente a través de la anécdota y el panegírico como subgéneros de la historia. La temporalidad pierde así su sentido político (Chatelet ibid:: 312). Igual que Platón y después Isócrates, Jenofonte busca la solución a los problemas de la ciudad, no en el estudio de su racionalidad histórica, sino en el hombre providencial (Chatelet ibid:: 362).

Tucídides, en cambio, define su obra como una posesión para siempre (I $22,4)$. Pero no se trata de que lo que él cuenta pueda repetirse de manera cíclica y por eso vaya a tener valor eterno para todas las épocas de la historia presente y futura; se trata más bien de conseguir la conservación del pasado en la escritura de la historia, es decir, su presencia como pasado (Chatelet 1962: 28). La naturaleza humana (Tucídides III 82, 2) es la que realmente tiene valor como elemento de referencia, pues en determinados momentos se muestra en su auténtica crueldad, como tendencia al dominio del más fuerte. Según sus palabras:

Recayeron sobre las ciudades con motivo de las revueltas muchas y graves calamidades, como las que suceden y sucederán siempre, mientras la naturaleza humana siga siendo la misma, con violencia mayor o menor y cambiando de aspecto de acuerdo con las alteraciones que se presenten en cada circunstancia.

Se puede entender el valor de referencia analógica del pasado (por ejemplo, en II 48, al referirse a la peste y las posibilidades de conocimiento de los casos futuros, así como en el mencionado pasaje de III 82), pero no como retorno del pasado (Momigliano 1969: 26-27) sino como rasgo que se muestra en los diferentes momentos históricos, con sus características bien distintas, en la sociedad homérica o minoica y en la ciudad democrática, que no es de ninguna manera el retorno de una realidad anterior. Como pensaría Montesquieu en el siglo XVIII (1942: 11-18), dado que los hombres han tenido en todo tiempo las mismas pasiones, aunque las ocasiones que provocan los grandes cambios varían, las causas son siempre las mismas. Se trata 
del establecimiento de referencias analógicas del comportamiento humano. Este aspecto lo volvería a tomar la Ilustración, como pensamiento contrario tanto al eterno retorno como al determinismo teleológico.

Ahora bien, en Tucídides todo el pasado es observado en clave de relaciones políticas (Plácido Suárez 1986: 39) y lo que se presenta como general no es lo mítico sino lo humano (Tucídides I 22, 4). Por eso la historia no puede ser mythôdes. El mito está fuera del tiempo, mientras que la historia se desarrolla en él. Pero precisamente es en el tiempo donde la victoria produce imperialismo, entre los persas y entre los atenienses. La política como elemento básico de la sociedad de la ciudad-Estado es el eje del desarrollo histórico, y por ello un fenómeno temporal. Por eso cree Tucídides que la historia puede aclarar el modo de funcionamiento de las sociedades humanas en su peculiaridad. La característica de la Guerra del Peloponeso estriba en que en ella se ha puesto más claramente de manifiesto cuáles son los rasgos principales de la naturaleza humana, más que en ningún otro momento histórico, que por ello no se repite ni se repetirá. La Guerra del Peloponeso es un acontecimiento único, como lo habían sido las Guerras Médicas para Heródoto. Pero ese acontecimiento único reviste tal importancia que la comprensión de sus circunstancias sí puede enseñar algo sobre el modo de funcionamiento de las sociedades humanas en el pasado y en el futuro. La claridad buscada por Tucídides se refiere tanto al pasado como al futuro (Scanlon 2002: 132), porque piensa que los mismos condicionantes pueden funcionar en otros momentos. Pero se trata de una preocupación inserta en el mundo de la política temporal, no en el de los mitos atemporales. Heródoto y Tucídides se interrogan sobre el pasado porque están preocupados por el futuro de la comunidad política (Chatelet 1962: 275). La diferencia entre la poesía y la historia no estriba tanto en la realidad o la irrealidad de los hechos pasados, cuanto en el carácter paradigmático de la primera (que los atemporaliza, dentro de las narraciones míticas o poéticas) o en el carácter analógico de la segunda (dentro del tiempo político de la ciudad). El hecho histórico está en su puesto cronológico, mientras que el mito poético es intemporal.

\section{PENSAMIENTO HISTÓRICO LAICO FRENTE A PENSAMIENTO PARADIGMÁTICO Y TELEOLOGÍA}

Aunque desde luego es cierto que en la historiografía griega no hay una dirección escatológica, sí resulta claro que refleja posibilidades futuras, como en Tucídides I 10, 2, sobre las perspectivas del conocimiento de la realidad espartana en un futuro hipotético después de que la ciudad fuera destruida, o en Polibio, cuando reflexiona sobre el final de Roma (Mazzarino 1974: II, 2, 
413-4). En Polibio, sin embargo, la teoría de las constituciones que se suceden cíclicamente como tal no influye sobre su visión de las guerras (Momigliano 1969: 28); el planteamiento teórico permanece en un plano diferente al plano narrativo. Hay por otra parte metáforas aisladas sobre la vuelta de los tiempos, como por ejemplo en Virgilio, redeunt Saturnia regna, vuelven los tiempos de Saturno; pero tales metáforas no afectan a las interpretaciones históricas. La historia más bien proporciona ejemplos analógicos, no paradigmas de acontecimientos futuros. La historia supera al mito en este aspecto.

Los antiguos no sintieron la necesidad de manifestarse acerca del contraste entre la concepción de un proceso cíclico y otro de tipo lineal (Mazzarino 1974: II, 2, 421). La palingenesia o regeneración pitagórica viene a ser una forma de expresión de las tradiciones procedentes del orfismo, pero con nuevas manifestaciones teóricas. Los ciclos se hallan, en efecto, presentes como elemento fundamental en el pitagorismo (ibid.: II, 2, 431), sobre todo en la teoría de las reencarnaciones, como etapas de un proceso general.

El tiempo cíclico estaría presente asimismo en el pensamiento platónico, en gran parte también heredero del orfismo, como puede verse sobre todo en el Político de Platọ́n, 269D-270A. Según Castoriadis (1999: 124), es Platón quien trata de eliminar del pensamiento griego la idea del ser como nacimiento y destrucción para imponer lo incorruptible. Se revelaría aquí el conflicto ideológico del platonismo en relación con las tradiciones materialistas y, en cierto modo, con la sofística. Con el mito de Crono, Platón trata de destruir la antropogonía de Demócrito, que debía de ser la dominante en el mundo intelectual del siglo v (Castoriadis 1999: 126). Platón se ha considerado, en efecto, el filósofo por excelencia de la "mentalidad primitiva" (Eliade 1968: 40). Con ello, el platonismo recupera también ciertos aspectos del pensamiento presocrático, como el de Anaximandro (Whitrow 1990: 59), cuando se refiere a la justicia en el retornar del tiempo, o el de Heráclito (Eliade 1968: 121), para quien sólo hay una naturaleza todos los días (en Diels y Kranz 1954: 22B106; Mazzarino 1974: II, 2: 416), ideas que tomarán de nuevo más tarde algunos de los estoicos (Eliade 1968: 124).

Frente a una concepción como la de Tucídides al referirse a los bárbaros y a los etolios, que consideran la civilización claramente como un fenómeno histórico, o la de Protágoras, que ve a la sociedad de los bárbaros de Ferécides como una sociedad predemocrática, el pensamiento paradigmático entiende la bestialidad del hombre primitivo como algo inamovible, según las reflexiones que recoge Critias (en Diels y Kranz 1954: 88B25), cuya actividad política se refiere precisamente al momento de los Treinta Tiranos tras la derrota de Atenas en la Guerra del Peloponeso. Ante ello, no hay más actitud posible que la representada por la represión, como ocurre igualmente en el texto del Pseudo-Jenofonte (Chatelet 1962: 254), que puede considerarse en 
la misma línea política que Critias. La posición evasiva de Aristófanes se caracteriza de la misma manera: por la búsqueda de la antihistoria, en la que no pase ni haya pasado nada (Chatelet ibid:: 256), la búsqueda de un mundo idealizado, ajeno al tiempo. Tales actitudes inmovilizan el pasado en la Edad de Oro (ibid.: 271). En la Grecia de la ciudad, por tanto, el contraste se marca entre lo positivo histórico de la política o lo negativo histórico de la Edad de Oro, que pretende el retorno.

Por su parte, en el pensamiento cristiano, Agustín ofrecerá el tiempo de la salvación frente al "tiempo cíclico de los griegos"; pero ello representa sólo al Hiponate, dentro de una determinada corriente que existe tanto entre griegos como entre judíos o cristianos (Momigliano 1969: 21). En el cristianismo de su tiempo, el proceso lineal se ha transferido al mundo de la salvación espiritual, del alma individual o de la ciudad colectiva, con lo que el proceso se reviste de aspectos escatológicos. No se puede oponer los griegos a los judíos de manera global en relación con la concepción cíclica o lineal. Como heredero del mundo platónico, Agustín identifica el tiempo con el universo, pero se opone al circuito de los tiempos en La Ciudad de Dios, XII 13 (Whitrow 1990: 89), y enuncia la concepción providencialista de la historia. La perspectiva se sitúa en el futuro, aspecto éste que sí está ausente de la concepción de los historiadores clásicos. La linealidad de los historiadores griegos no es desde luego escatológica, sino histórica.

Platón, en el mito del reino de Crono del Político, 268d-277b, lo que trata de destruir es la idea de autoconstitución de la especie humana que existía en los pensadores griegos del s. v. Piensa que son sólo los dioses los que permiten a los humanos sobrevivir y los que crearon todos los instrumentos de su supervivencia (Castoriadis 1999: 127). Para Platón, no existe proyecto basado en la historia, porque el resultado de la historia es su presente negativo. No confía en un proyecto simplemente humano, histórico. En cambio, el hombre democrático de Protágoras es un producto histórico. La plasmación cronográfica del espíritu sofístico estaría representada por Hipias (Samuel 1972: 190), que pretende sistematizar la linealidad en la periodización a través de las Olimpíadas.

Aristóteles, en la primera parte de la Constitución de Atenas, prepara igualmente la comprensión de la linealidad (Chatelet 1962: 336-7), lo mismo que hace en la Metafisica con la Filosofía. Las realidades presentes encuentran su explicación en la linealidad sistemática del pasado. Por ello es importante tener en cuenta la concepción rectilínea de Plotino, expuesta de forma polémica contra los gnósticos (II 9, 3) y contra los cristianos, que eran quienes afirmaban el final de los tiempos (Mazzarino 1974: II, 2, 422). Así pues, la linealidad se presenta no sólo como alternativa a la ciclicidad, sino también como alternativa a la teleología. 
Las fundaciones de eras a lo largo de la Historia de Grecia son un claro indicativo de una concepción no cíclica del tiempo. Aunque entre los griegos no llegó a imponerse la existencia de un solo punto de partida que sirviera de referencia para todas ellas, no dependió esta diversidad tanto de la concepción del tiempo como del propio desarrollo histórico, que requirió diferentes calendarios como requirió diferentes sistemas monetarios. Por ello, para los griegos, aun dentro de una percepción lineal, había múltiples puntos de partida; la fundación de Siracusa, por ejemplo, se convirtió en el comienzo de la historia de las demás fundaciones coloniales de Sicilia: "a los cuarenta y cinco de la fundación de Siracusa" escribe Tucídides (VI 4, 3) (Mazzarino 1974: II, 2, 427). En consecuencia, es necesario distinguir entre la concepción del tiempo de los pitagóricos, elaborada sobre base cíclica y "psicogónica" - de acuerdo con las características generales de su pensamiento-, y la de Tucídides (Mazzarino ibid.: II, 2, 435).

Como forma específica de concepción histórica con base en el ciclo, existe la idea del milenio que habría transcurrido entre la caída de Troya y las empresas de Alejandro en la obra de Duris de Samos (ibid: II, 2, 438). Pero, como recuerda Mazzarino (ibid.), aunque se produce así la renovación de la victoria griega en Asia, no por ello vuelve a empezar con los sucesores del macedonio la época posterior a la guerra de Troya.

Lo que sí importa en la historiografía antigua es la sincronía como forma esencial de datación (ibid.: II, 2, 439), aunque se trate de la coincidencia casual de dos o más acontecimientos. Tucídides parte de la sincronía pero, luego (V 20), defiende la datación por veranos e inviernos, precisamente para evitar los errores derivados de la imprecisión del ejercicio del cargo dentro del año natural (Mazzarino ibid.: II, 2, 442). Desde luego, Tucídides, en su concepción del tiempo, se separa, como en otros aspectos, del resto de la historiografía griega —como la de Jenofonte o incluso Polibio-, que seguía sin comprender los planteamientos cronográficos de Timeo. La concepción de Tucídides responde a un momento histórico preciso y se contrapone a otras, que fueron las mayoritarias y se reprodujeron en la tradición clásica dominante.

En la concepción general de la historia en Tucídides, la temporalidad es principalmente el marco del acontecimiento bélico (Chatelet 1962: 116) y la guerra es factor de inteligibilidad del proceso histórico (Chatelet 1962: 119), porque se relaciona con los demás aspectos históricos, sociales y políticos: en la guerra se revela la naturaleza humana. Como centro para la comprensión de la historia, la guerra se desenvuelve en una sucesión marcada por los veranos e inviernos.

La combinación entre la sincronía como coincidencia explicativa y la diacronía se consolida en la época de Julio César; por ejemplo, en Diodoro 
(I 5), quien tuvo en cuenta la continuación y la sincronía (Mazzarino 1974: II, 2, 449). Diodoro sabía que sólo después de la Guerra de Troya era posible hacer uso de una sucesión ordenada. Otro ejemplo de sucesión rectilínea en el siglo I a.C. es el de Cástor de Rodas (en Jacoby 1929: II, 250F1-2), que comprende la época pretroyana. Este autor incluye en el fragmento F1 la basileía o poder hegemónico de árabes y asirios desde 2123; en el F2, la de los sicionios desde Egialeo, en el mismo año. Continúa luego con otras listas cronológicas. Diodoro, en cambio, prescinde de esta cronología, por no considerarla segura. Pero lo importante es que en este período —en que las transiciones históricas se hacen patentes- vuelve, si bien de forma relativamente efímera, la percepción del tiempo como sucesión que se origina a partir de un momento y continúa de modo lineal, aunque no naturalmente dirigida a un final determinado de modo providencialista.

En definitiva, el pensamiento histórico laico sólo existe en la antigüedad en la Atenas del siglo v a.C., aunque deja huellas en otras obras históricas. $\mathrm{Su}$ vigencia se relaciona con el momento en que las transformaciones históricas afectaban a las estructuras colectivas, cuando el papel individual resultaba menos protagonista, cuando las diferencias entre el pasado y el presente se hacían tan patentes como para señalar con claridad que no todo podía reducirse a ciclos como los que ofrece el tiempo que se percibe en el estudio del cosmos.

\section{BIBLIOGRAFÍA CITADA}

CASTORIADIS, C. 1999. Sur le Politique de Platon. París: Seuil.

CHATELET, F. 1962. La naissance de l'bistoire. La formation de la pensée historienne en Grèce. París: Éditions de Minuit.

Diels, H., y W. KRANZ. 1954. Die Fragmente der Vorsokratiker. Berlín: Weidmann.

ElIADE, M. 1968. El mito del eterno retorno [1951]. Buenos Aires y Barcelona: Emecé.

FinleY, M. I. 1977. "Mito, memoria e historia", en M. I. Finley, Uso y abuso de la bistoria: 11-44. Barcelona: Crítica.

Hunter, V. J. 1982. Past and Process in Herodotus and Tbucydides. Princeton: Princeton University Press.

JACOBY, F. 1929. Die Fragmente der Griechischen Historiker. Berlín: Weidmann.

Janicaud, D. 1997. Kronos. Pour l'intelligence du partage temporel. París: Grasset.

Mazzarino, S. 1974. Il pensiero storico classico. Cuarta edición. Roma: Laterza.

Momigliano, A. 1969. "Time in Ancient Historiography", en A. Momigliano, Quarto contributo alla storia degli studi classici e del mondo antico: 1-23. Roma: Edizioni di Storia e Letteratura.

MONTESQUiEU, CH. DE SECONDAT, BARÓN DE. 1942. Grandeza y decadencia de los romanos. Madrid: Espasa-Calpe, Austral.

Plácido SuÁReZ, D. 1984. "Protagoras et la société athénienne: le mythe de Prométhée». Dialogues d'Histoire Ancienne 10: 161-178.

-. 1986. "De Heródoto a Tucídides". Gerión 4: 17-46. 
-. 1999a. "La douleía en Heródoto: imperialismo persa y relaciones de dependencia", en Departamento de Filología Clásica del Instituto de Filología del CSIC (ed.), Tês philies táde dôra. Miscelánea léxica en memoria de Conchita Serrano: 681-688. Madrid, CSIC.

- 1999b. "Los usos del arcaísmo en la ciudad democrática", en Homenaje al Profesor Montenegro. Estudios de Historia Antigua: 75-85. Valladolid: Universidad.

SAMUEL, A. E. 1972. Greek and Roman Chronology. Calendars and Years in Classical Antiquity. Múnich: Beck.

SCANlon, T. F. 2002. "The Clear True' in Thucydides 1.22.4". Historia 51: 131-148.

THOMPSON, E. P. 1979. Tradición, revuelta y consciencia de clase. Estudios sobre la crisis de la sociedad preindustrial. Traducción de Eva Rodríguez. Barcelona: Crítica.

Thomson, G. 1946. Aeschylus and Athens. A Study in the Social Origins of Drama. Londres: Lawrence \& Wishart.

VIDAL-NAQueT, P. 1981. "Temps des dieux et temps des hommes", en P. Vidal-Naquet, Le chasseur noir. Formes de pensée et formes de société dans le monde grec: 69-94. París: Maspero.

Whitrow, G. J. 1990. El tiempo en la Historia. La evolución de nuestro sentido del tiempo y de nuestra perspectiva temporal. Barcelona: Crítica. 